\title{
Discovery and Biosynthesis of Persiathiacins: Unusual \\ Polyglycosylated Thiopeptides Active against Multi-drug resistant Tuberculosis
}

Yousef Dashti, ${ }^{\text {at* }}$ Fatemeh Mohammadipanah, ${ }^{\mathrm{b}}$ Matthew Belousoff, ${ }^{\mathrm{c}}$ Anthony Vocat, ${ }^{\mathrm{d}}$

Daniel Zabala, ${ }^{\text {a }}$ Christopher D Fage, ${ }^{\text {a }}$ Isolda Romero-Canelon, ${ }^{\text {ah }}$ Boyke Bunk,,${ }^{\text {e }}$ Cathrin

Spröer, ${ }^{\mathrm{e}}$ Jörg Overmann, ${ }^{\mathrm{e}}$ Stewart T Cole ${ }^{\mathrm{d} *}$ and Gregory L Challis ${ }^{\text {afg* }}$

\footnotetext{
${ }^{a}$ Department of Chemistry, University of Warwick, Coventry CV4 7AL, United Kingdom

${ }^{b}$ Department of Microbiology, School of Biology, College of Science, University of Tehran, Tehran, Iran

c Infection and Immunity Program, Biomedicine Discovery Institute and Department of Microbiology, Monash University, Clayton, Australia

${ }^{d}$ Global Health Institute, Ecole Polytechnique Fédérale de Lausanne, Station 19, 1015 Lausanne, Switzerland

e Leibniz-Institute DSMZ-German Collection of Microorganisms and Cell Cultures, 38124 Braunschweig, Germany, and Technical University of Braunschweig, Braunschweig, Germany

${ }^{\mathrm{f}}$ Warwick Integrative Synthetic Biology Centre, University of Warwick, Coventry CV4 7AL, United Kingdom

${ }^{g}$ Department of Biochemistry and Molecular Biology, Monash University, Clayton, Australia

${ }^{\mathrm{h}}$ School of Pharmacy, Institute of Clinical Sciences, University of Birmingham, Birmingham B15 2TT, United Kingdom

$¥$ Current addresses: Y.D. The Centre for Bacterial Cell Biology, Biosciences Institute, Medical School, Newcastle

University, Newcastle upon Tyne, NE2 4AX, UK; S.T.C. Institut Pasteur, 25 - 28 rue du Docteur Roux, Paris, France

*Corresponding authors: dashti.yousef@gmail.com and g.l.challis@warwick.ac.uk
}

\section{Abstract}

Thiopeptides are ribosomally synthesized and posttranslationally modified peptides (RiPPs) that exhibit a range of useful biological activities. Herein, antimicrobial activity screens with a library of Actinobacteria extracts led to discovery of the novel thiopeptide antibiotics persiathiacins A and B, originating from Actinokineospora sp. UTMC 2475 and Actinokineospora sp. UTMC 2448. Persiathiacin A displayed potent activity against methicillin-resistant Staphylococcus aureus (MRSA) and several Mycobacterium tuberculosis strains, including drug-resistant and multidrug-resistant clinical isolates, but no significant toxicity towards an ovarian cancer cell line. On the basis of in vitro translation assays, the observed antibacterial activity could be attributed to inhibition of ribosomal protein biosynthesis. Philipimycin is the only other polyglycosylated thiopeptide reported and nothing is known about its biosynthesis. We therefore sequenced and analysed the genome of 
Actinokineospora sp. UTMC 2448 to identify the biosynthetic gene cluster responsible for persiathiacin production. Through in vitro and in vivo experiments, we confirmed the role of this gene cluster in persiathiacin biosynthesis and identified a cytochrome $\mathrm{P}_{450}$ enzyme that introduces a site for deoxysugar attachment via thiazole hydroxylation. On the basis of several promising characteristics, persiathiacins $\mathrm{A}$ and $\mathrm{B}$ are good candidates from which new therapeutics may be engineered.

\section{Introduction}

During the last decade, Mycobacterium tuberculosis infections caused about 30 million deaths worldwide, ranking it as the second most deadly pathogen after the human immunodeficiency virus (HIV). ${ }^{1}$ Currently, multidrug regimens for a course of 6-12 months are prescribed to treat $M$. tuberculosis infections; however, due to difficulties with dosing, side effects, and, more importantly, emergence of multi- and extensively drug-resistant strains, new, more effective antibiotics must be developed to combat this critical-priority pathogen. ${ }^{2-3}$

Thiopeptide antibiotics belong to the family of ribosomally synthesized and posttranslationally modified peptides (RiPPs) in which a ribosomally synthesized precursor peptide undergoes extensive modification by a series of highly diverse biosynthetic enzymes to yield the final product. ${ }^{4-5}$ The precursor peptide consists of an $\mathrm{N}$-terminal leader peptide that acts as recognition motif for most of the posttranslational modification enzymes and a C-terminal core peptide that is incorporated into the mature product(s). ${ }^{5-6}$ Common posttranslational modifications of thiopeptides include azole formation via cyclodehydration/oxidation, selective dehydration of serine and threonine residues, and macrocyclization through [4+2] cycloaddition. Some thiopeptides are additionally modified by tailoring enzymes, which catalyse macrocyclization or 
introduce hydroxy, methyl, indolyl, or quinaldyl moieties onto the core peptide. ${ }^{7-13}$ Many thiopeptide natural products possess potent activity against several clinically relevant bacterial strains, in addition to antitumor and immunosuppressive properties. ${ }^{14}$ For instance, nosiheptide, nocathiacin, and philipimycin, which are representative of series e thiopeptides, show potent activity against MRSA and/or clinical isolates of $M$. tuberculosis (Figure 1). ${ }^{15-17}$ Despite their promising biological activities, thiopeptides have failed to reach the clinic due to poor aqueous solubility and gastrointestinal absorption. To overcome this barrier, several strategies, including biosynthetic pathway engineering, chemical synthesis, and semisynthetic derivatization, have been applied to produce analogues with improved pharmacokinetic properties. ${ }^{18}$
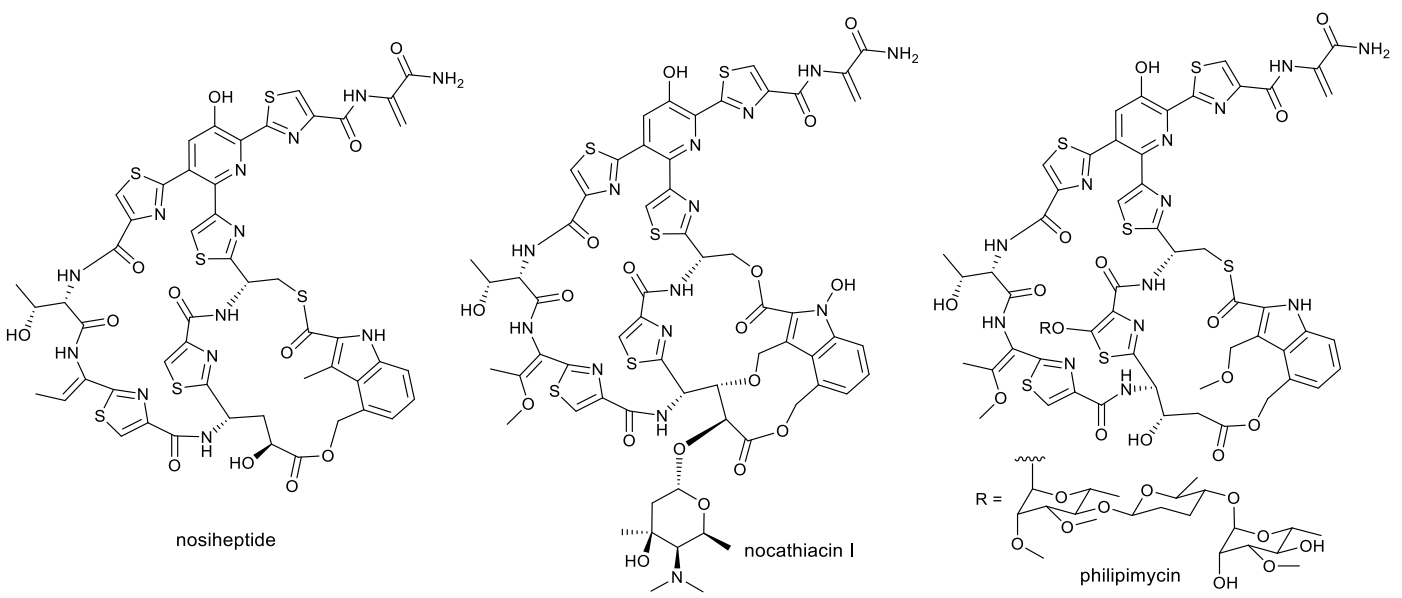

Figure 1. Structures of the nosiheptide, nocathiacin and philipimycin antibiotics, which belong to the series e thiopeptides.

Herein, we report the chemical structures, biosynthetic pathways, and biological activities of the novel glyco-thiopeptide antibiotics persiathiacins $\mathrm{A}$ and $\mathrm{B}$, which were discovered in screens of bacterial extracts against MRSA. As glycosylation of nocathiacin (via biotransformation) was shown to improve solubility, ${ }^{19}$ the highly modified sugars decorating persiathiacins are promising targets for biosynthetic engineering efforts to improve drug properties, such as water solubility and bioavailability. 


\section{Results and discussion}

\section{Isolation and structure elucidation of persiathiacins $A$ and $B$}

In the course of a search for novel anti-MRSA natural products, extracts of a collection of actinomycete strains isolated from various parts of Iran were screened against MRSA. Ethyl acetate extracts of Actinokineospora sp. UTMC 2475 and Actinokineospora sp. UTMC 2448 were found to exhibit potent anti-MRSA activity. The metabolic profiles of these two strains were revealed to be identical by UHPLC-ESI-Q-TOF-MS. To identify the active metabolite, Actinokineospora sp. UTMC 2448 was cultured on solid ISP2 media for 7 days, followed by ethyl acetate extraction for fractionation by semipreparative HPLC. Persiathiacin A was purified from an active anti-MRSA fraction. A molecular formula of $\mathrm{C}_{80} \mathrm{H}_{91} \mathrm{~N}_{13} \mathrm{O}_{30} \mathrm{~S}_{5}$ was determined on the basis of positive ion mode HR-ESI-MS and NMR data, and a planar structure was determined using 1D/2D NMR experiments (Figure 2, Figures S1 and S3-S7, Table S1). Characteristic alpha protons at $\delta_{H}$ 4.21, 5.62, and 5.80, which showed HSQC correlations to the alpha carbons at $\delta_{C} 56.2,48.6$, and 48.7 as well as COSY correlations to the exchangeable $\mathrm{NH}$ protons at $\delta_{H} 7.87,7.89$, and 8.24, indicated amino acid residues in the structure. Four thiazoles (including three carboxy thiazoles) and a tetrasubstituted pyridine ring were identified from their distinctive $\mathrm{sp}^{2}$ singlet proton resonances, their directly bonded carbon chemical shifts, and their HMBC correlations. The characteristic signal of the $\mathrm{sp}^{2}$ methylene of dehydroalanine (Deala) at $\delta_{C} 104.8$, which showed HSQC correlations to two protons at $\delta_{H} 5.53$ and 6.47 , was also identified in the ${ }^{13} \mathrm{C}$ NMR spectrum of persiathiacin. This was further confirmed through ${ }^{2} J$ HMC correlation of the methylene protons to the quaternary carbon of Deala-C2 at $\delta_{C} 133.5$ and ${ }^{3} J$ correlation to the carbonyl carbon $($ Deala-C $=\mathrm{O})$ at $\delta_{C} 166.5$. Taken together, these experiments indicated that persiathiacin contains a thiopeptide backbone. 

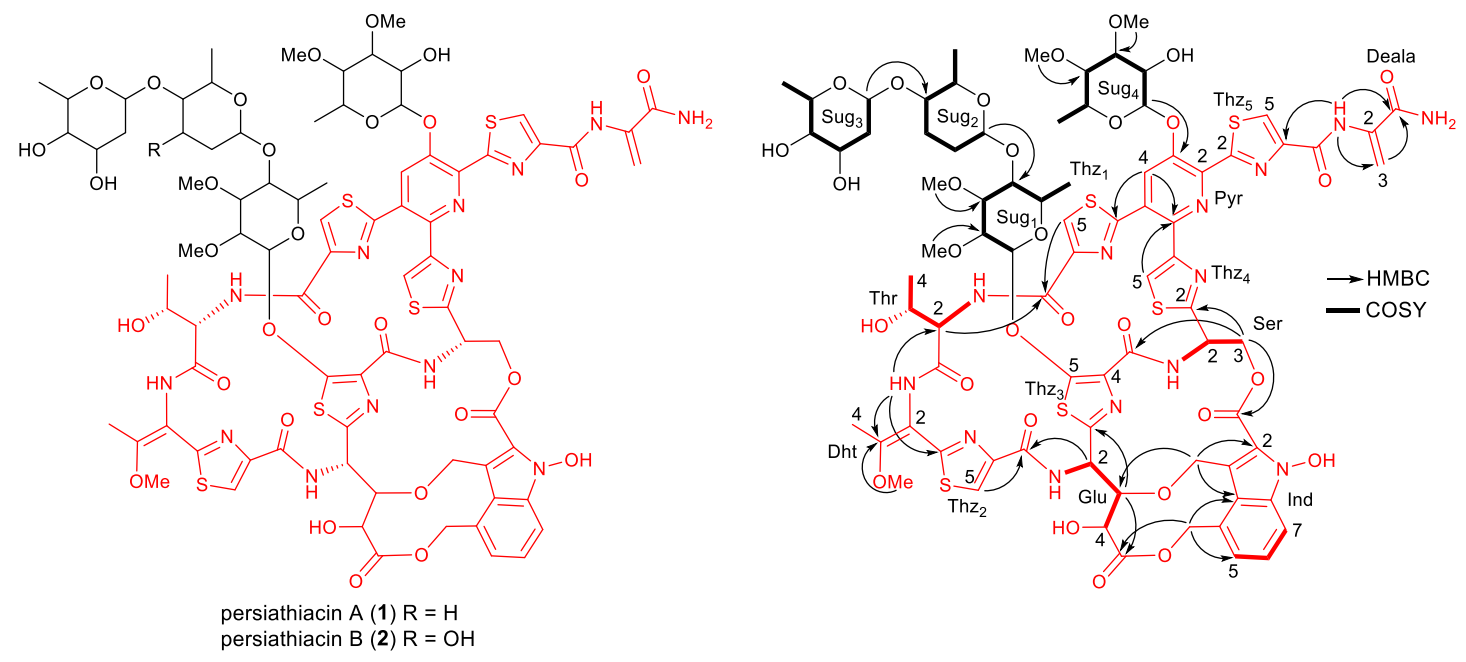

Figure 2. Structures of persiathiacin A (1) and persiathiacin B (2) (left panel). Structure of persiathiacin $\mathrm{A}$, annotated with COSY and key HMBC correlations (right panel).

The following NMR evidence revealed that the core peptide is similar to that of nocathiacins ${ }^{20}:{ }^{3} J$ correlation between an OMe proton $\left(\delta_{H} 3.78\right)$ and the Dht-C3 carbon $\left(\delta_{C} 158.7\right)$ indicated a methoxy group on Dht-C $3 ;{ }^{3} J$ correlation between an Ind-C3b methylene proton $\left(\delta_{H} 4.17\right)$ and the Glu-C3 carbon $\left(\delta_{C} 82.9\right)$ and between a Glu-C3 methine proton $\left(\delta_{H} 3.65\right)$ and Ind-C3b carbon $\left(\delta_{C} 65.9\right)$ revealed a third bridge between the indole ring and core peptide; a hydroxy group attached to the nitrogen of the indole ring was identified through ${ }^{3} J$ correlation of an exchangeable hydroxy proton $\left(\delta_{H} 10.46\right)$ and the Ind-C2 carbon $\left(\delta_{C} 127.0\right)$; the presence of a serine residue in the structure was identified through the distinctive chemical shift of the Ind-C $=\mathrm{O}$ carbon $\left(\delta_{C} 161.4\right)$ and comparison to those reported for nocathiacin I (161.1 ppm in DMSO- $\left.d_{6}\right)$ and nosiheptide (181.80 ppm in DMSO- $\left.d_{6}\right)$ as well as the Ser-C3 carbon $\left(\delta_{C} 64.5\right)$ and comparison to the reported values for nocathiacin I (63.3 ppm in DMSO- $\left.d_{6}\right)$ and nosiheptide $(29.5 \mathrm{ppm}$ in DMSO-d6). ${ }^{20-21}$

In addition to the resonances of the core peptide, four distinctive anomeric carbon resonances at $\delta_{C} 100.4,101.1,101.9$, and 102.2, with HSQC correlations to anomeric protons at $\delta_{H} 5.18,4.43,5.41$, and 4.61, respectively, suggested a glycosylated peptide. 
Four discrete coupled proton spin systems for the deoxyhexose residues were established through COSY correlations in conjunction with the ${ }^{1} \mathrm{H}-{ }^{1} \mathrm{H}$ coupling constants and HMBC correlations (Figure 2). The identified fragments were pieced together according to $\mathrm{HMBC}$ correlations. Connection of sugar 1 to the thiazole 3 was assigned through the ${ }^{3} J$ correlation of the sugar 1 anomeric proton $\left(\delta_{H} 5.41\right)$ to the Thz3C5 carbon $\left(\delta_{C} 160.3\right)$. The positions of the methoxy moieties on sugar 1 were assigned based on the ${ }^{3} J$ correlation of C2-OMe protons $\left(\delta_{H} 3.48\right)$ to the Sug1-C2 carbon $\left(\delta_{C}\right.$ 76.0) and C3-OMe protons $\left(\delta_{H} 3.42\right)$ to the Sug1-C3 carbon $\left(\delta_{C} 80.1\right)$. The amicetose moiety (sugar 2) was connected to sugar 1 according to HMBC correlations between the anomeric proton of Sug2-C1 $\left(\delta_{H} 4.61\right)$ and the Sug1-C4 carbon $\left(\delta_{C} 77.0\right)$ as well as the Sug1-C4 proton $\left(\delta_{H} 3.46\right)$ and the Sug2-C1 anomeric carbon $\left(\delta_{C} 102.2\right)$. The same strategy was applied to identify the connectivity of the olivose moiety (sugar 3) to sugar 2. HMBC correlations were observed between the sugar 3 anomeric proton $\left(\delta_{H} 4.43\right)$ and the Sug2-C4 carbon $\left(\delta_{C} 80.60\right)$ and also between the Sug2-C4 proton $\left(\delta_{H} 3.08\right)$ and the Sug3-C1 anomeric carbon $\left(\delta_{C} 101.1\right)$. Sugar 4 was placed on the pyridine ring based on both the ${ }^{3} J$ HMBC correlation between the anomeric proton $\left(\delta_{H} 5.18\right)$ to the Pyr-C3 carbon $\left(\delta_{C} 149.0\right)$ and a ROESY correlation between the Sug4-C1 proton and Pyr-C4 proton $\left(\delta_{H} 7.77\right)$. Positions of both methoxy groups on sugar 4 were identified from HMBC connections of Sug4-C3-OMe protons $\left(\delta_{H} 3.45\right)$ to the Sug4-C3 carbon $\left(\delta_{C} 84.2\right)$ and Sug4-C4-OMe protons $\left(\delta_{H} 3.51\right)$ to the Sug4-C4 carbon $\left(\delta_{C} 77.6\right)$.

In addition to persiathiacin $\mathrm{A}$, a minor metabolite with a mass of $16 \mathrm{Da}$ higher than that of persiathiacin A was also purified from the active fractions of the Actinokineospora sp. UTMC 2448 extract. The molecular formula $\mathrm{C}_{80} \mathrm{H}_{91} \mathrm{~N}_{13} \mathrm{O}_{31} \mathrm{~S}_{5}$, obtained from HRESI-MS and NMR data, indicated the presence of an additional oxygen atom in the structure. Comparative analysis of the NMR data of persiathiacin A and this minor 
compound (referred to as persiathiacin B) revealed almost identical chemical shifts, with the exception of the proton and carbon resonances of sugar 2 (Figure 2, Figures S2 and S8-S13, Table S2). Detailed analysis of 1D/2D NMR data revealed an olivose moiety instead of an amicetose at the sugar 2 position of persiathiacin B.

\section{Identification and analysis of the persiathiacin biosynthetic gene cluster}

In order to identify the biosynthetic gene cluster responsible for the production of persiathiacins A and B, the genome of Actinokineospora sp. UTMC 2448 was sequenced using SMRT sequencing technology. A final circular genome consisting of 7,012,397 bp was obtained by this approach (GenBank accession number CP031087). Genomic analysis by antiSMASH ${ }^{22}$ identified 32 putative biosynthetic gene clusters for specialized metabolites (Table S3). A putative thiopeptide-polysaccharide biosynthetic gene cluster (cluster 11; Table S3) containing 33 genes was postulated to direct persiathiacin biosynthesis (Figure 3). BLAST searches revealed a high degree of homology between the persiathiacin biosynthetic gene products PerA-PerP and the precursor peptide and posttranslational modification enzymes of nosiheptide (NosANosP) and nocathiacin (NocA-NocP). Counterparts of five additional genes in the persiathiacin gene cluster (perR and perT-perV) are found in the nocathiacin system (nocR and nocT-nocV) but not the nosiheptide system (Figure 3). Furthermore, the persiathiacin cluster harbours the perS1-perS12 genes responsible for the biosynthesis and transfer of sugars to the modified core peptide (Table S4).

Detailed analysis of perA-perV and perS1-perS12 allowed us to propose a biosynthetic pathway for persiathiacin (Figures 3 and 6). First, perM is translated as a 49 amino acid (aa) precursor peptide consisting of a 36 aa $\mathrm{N}$-terminal leader peptide and a 13aa C- 
terminal core peptide with sequence $\mathrm{S}_{1} \mathrm{C}_{2} \mathrm{~T}_{3} \mathrm{~T}_{4} \mathrm{C}_{5} \mathrm{E}_{6} \mathrm{C}_{7} \mathrm{~S}_{8} \mathrm{C}_{9} \mathrm{~S}_{10} \mathrm{C}_{11} \mathrm{~S}_{12} \mathrm{~S}_{13}$. The sequence of core peptide is consistent with the structure identified by NMR analysis.
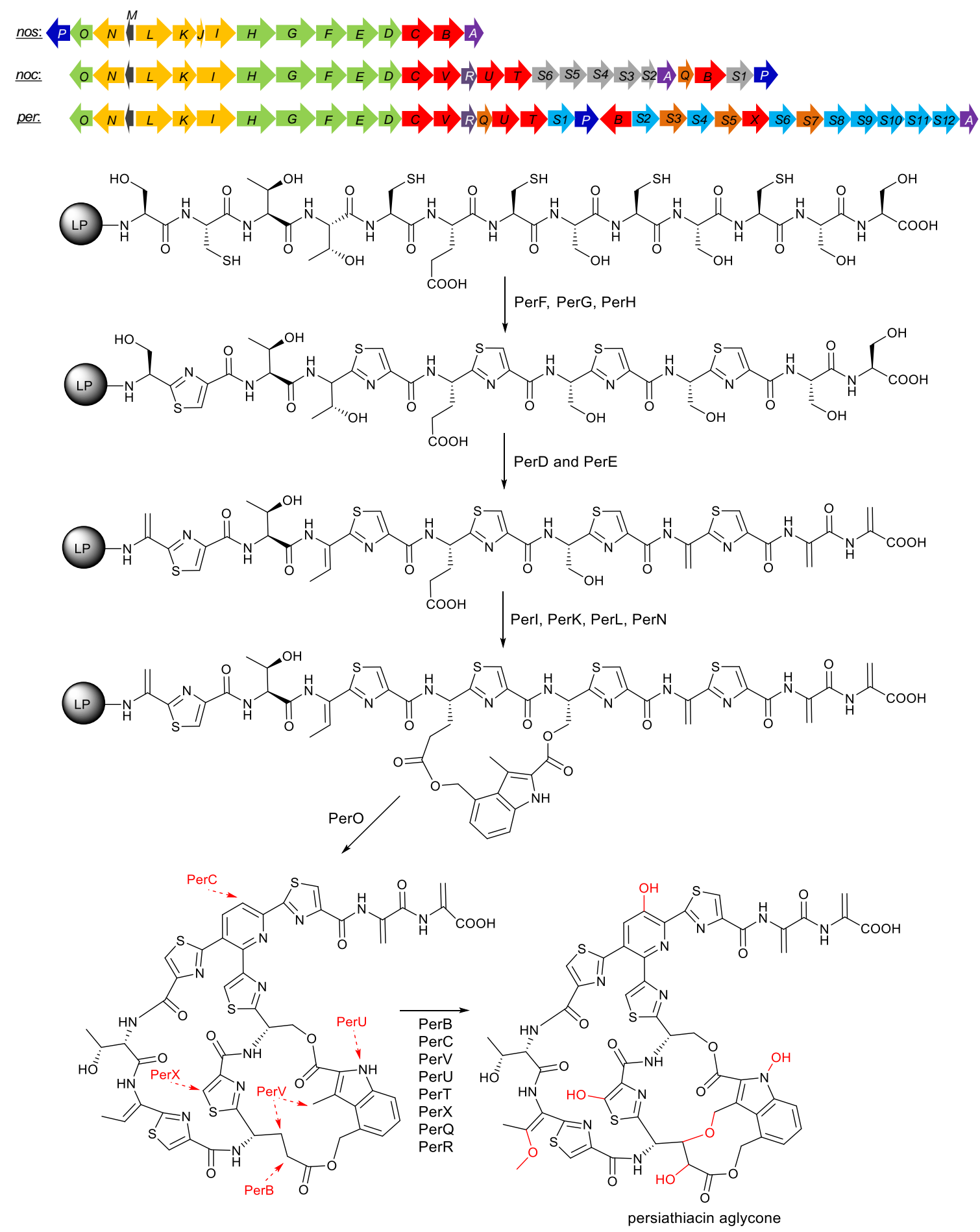

Figure 3. Comparison of the biosynthetic gene clusters of nosiheptide, nocathiacin, and persiathiacin (top panel). The proposed biosynthesis of persiathiacin aglycone starts with transcription and translation of perM to yield a precursor peptide comprised of a leader peptide (LP) and a core peptide (chemical structure depicted). The core peptide undergoes a series of modifications by several enzymes in the persiathiacin gene cluster. See main text for further details. 
Cyclodehydration of the cysteine residues by PerG and PerH, followed by dehydrogenation catalysed by PerF, yields the thiazole rings of persiathiacin. ${ }^{7}$ Dehydratases PerD and PerE further modify the core peptide through selective dehydration of Ser1, Ser10, Ser12, Ser13, and Thr4.

Four enzymes encoded by perI, perK, perL, and perN are responsible for the production of 3,4-dimethylindolic acid (DMIA) from L-tryptophan and its attachment to the core peptide (Figures 3 and S14). The radical $S$-adenosylmethionine (SAM) enzyme PerL transforms L-tryptophan into 3-methyl-2-indolic acid (MIA) through an unusual constitutional isomerisation of a C-C bond. ${ }^{23-31}$ In nosiheptide biosynthesis, the ATPdependent NosI activates and transfers MIA to the free thiol of the phosphopantetheine arm of the acyl carrier protein NosJ; NosJ then delivers MIA to NosK for transfer to Cys8 of nosiheptide (Figure S14). ${ }^{32-34}$ In the persiathiacin and nocathiacin gene clusters, only PerI (NocI) and PerK (NocK) are present, and no standalone acyl carrier protein similar to NosJ has been identified. Pairwise comparison of the NosJ, PerI, and PerK sequences revealed similarity between NosJ and the C-terminus of PerK. In a BLAST search of NosJ, similarity to the C-terminal region of NocK was previously observed. ${ }^{32}$ Thus, it appears that in persiathiacin and nocathiacin biosynthesis, the acyl carrier protein is fused to PerK/NocK, which transfers MIA from PerI/NocI to the catalytic site of PerK/NocK for attachment to Ser8 of persiathiacin or nocathiacin (Figure S14). Subsequently, another radical SAM methyltransferase, PerN, transfers C1 from SAM to the $\mathrm{C} 4$ of MIA, generating a reactive electrophilic intermediate which is then attacked by the Glu6 carboxylate of persiathiacin to form an ester linkage. ${ }^{35}$ Finally, PerO (>50\% similar to NosO and $\mathrm{NocO}$ ) is responsible for macrocyclization of persiathiacin through a $[2+4]$ cycloaddition and formation of a pyridine ring. ${ }^{36-37}$ 
Of the six $\mathrm{P}_{450}$ enzymes encoded in the persiathiacin gene cluster, two (PerB and PerC) are homologous to NosB (NocB) and NosC (NocC), which hydroxylate Glu6 $\mathrm{C} \gamma$ and $\mathrm{C} 3$ of the pyridine ring, respectively. ${ }^{13}$ Cytochrome $\mathrm{P}_{450}$ enzymes PerV, PerU, and PerT in the persiathiacin gene cluster are homologous to NocV, NocU, and NocT of the nocathiacin gene cluster but are without counterparts in the nosiheptide system. Similar to NocV, PerV could be responsible for formation of the ether linkage between the indole ring and core peptide of persiathiacin via a mechanism yet to be identified. ${ }^{38}$ Similarly, PerU is involved in $N$-hydroxylation of indolic moiety, a function which has been proposed for the homologous enzyme NocU. ${ }^{39}$ Comparison of the structures of persiathiacin and nocathiacin (Figure 4) suggests the $\mathrm{P}_{450}$ enzyme PerT (NocT) is responsible for hydroxylation of C3 of Dht, followed by methylation catalysed by the methyltransferase PerQ (NocQ).

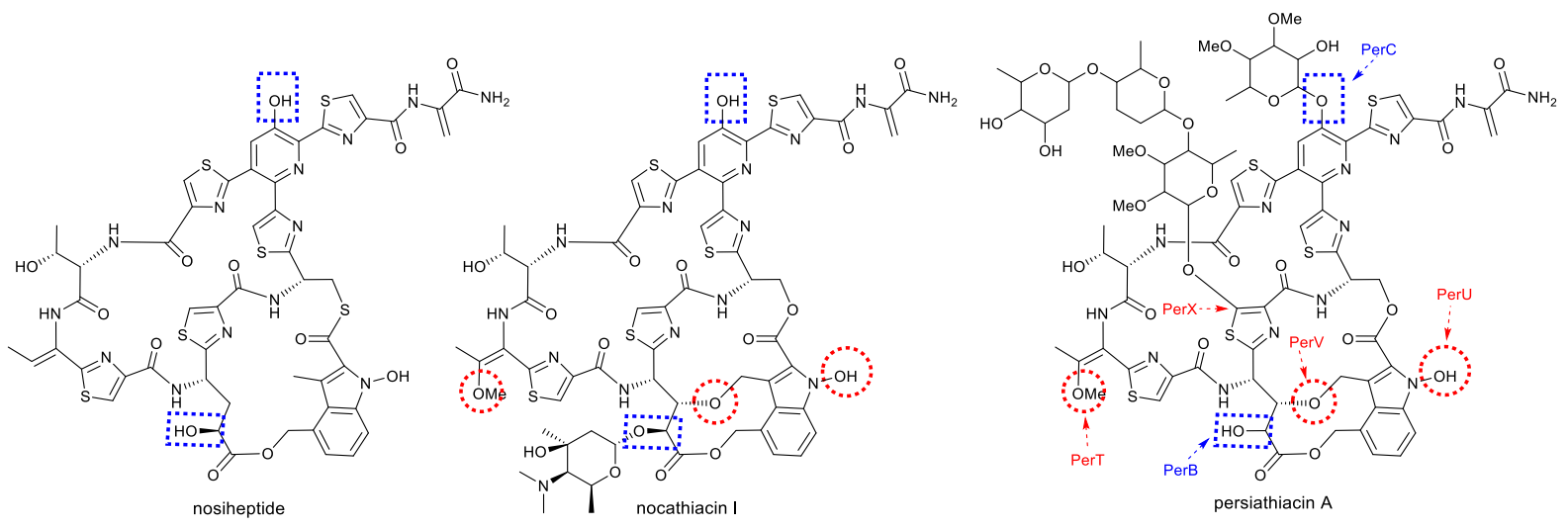

Figure 4. Identification of PerX, a new $\mathrm{P}_{450}$ enzyme, through comparative analysis of the nosiheptide, nocathiacin, and persiathiacin biosynthetic gene clusters. Regions of interest are highlighted in the structures: blue dashed boxes indicate the hydroxylation sites of homologous cytochrome $\mathrm{P}_{450}$ enzymes (NosB/NocB/PerB and NosC/NocC/PerC) found in the nosiheptide, nocathiacin, and persiathiacin systems; red dashed circles indicate the hydroxylation sites of the $\mathrm{P}_{450}$ enzymes (NocT/PerT, NocV/PerV, and NocU/PerU) present in the nocathiacin and persiathiacin systems but not that of nosiheptide. The $\mathrm{P}_{450}$ enzyme PerX, which is only present in the persiathiacin gene cluster, presumably hydroxylates the thiazole moiety.

PerX is the only persiathiacin cytochrome $\mathrm{P}_{450}$ for which a homolog is lacking in the nosiheptide and nocathiacin biosynthetic gene clusters. We hypothesised that this enzyme hydroxylates C5 of Thz3, which is the attachment site of a highly modified 
trisaccharide. To test this hypothesis, recombinant His 6 -tagged PerX was expressed, purified, and incubated with nosiheptide in the presence of spinach ferredoxin-NADP ${ }^{+}$ reductase, spinach ferredoxin, and NADPH at room temperature for $3 \mathrm{~h}$. UHPLC-ESIQ-TOF-MS analysis revealed a product of $m / z 1238.1493[\mathrm{M}+\mathrm{H}]^{+}$(calcd for $\mathrm{C}_{51} \mathrm{H}_{44} \mathrm{~N}_{13} \mathrm{O}_{13} \mathrm{~S}_{6}, 1238.1500$ ), indicating the addition of one oxygen atom in the molecular formula compared to nosiheptide with $m / z 1222.1542[\mathrm{M}+\mathrm{H}]^{+}$(calcd for $\mathrm{C}_{51} \mathrm{H}_{44} \mathrm{~N}_{13} \mathrm{O}_{12} \mathrm{~S}_{6}, 1222.1551$ ) (Figure 5). In attempt to obtain adequate quantities of hydroxylated nosiheptide for NMR analysis, $\operatorname{per} X$ was overexpressed in the nosiheptide producing strain Streptomyces actuosus ATCC25421 (Figure 5). The expected product was observed by UHPLC-ESI-Q-TOF-MS; however, the yield of the hydroxylated product was inadequate for full NMR characterization, likely because nosiheptide is not the natural substrate of PerX.
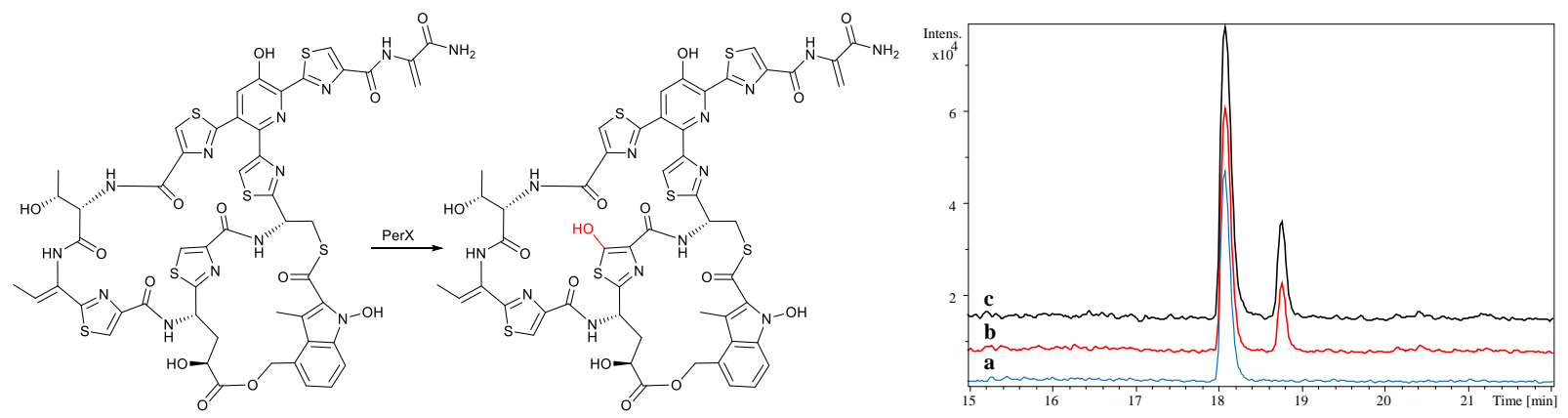

Figure 5. The cytochrome $\mathrm{P}_{450}$ enzyme PerX was hypothesized to hydroxylate $\mathrm{C} 5$ of the central thiazole ring in nosiheptide, similar to that of persiathiacin (left panel; hydroxyl group colored red). Extracted ion chromatograms (right panel) of nosiheptide and the hydroxylated product are shown for: a) nosiheptide incubated with boiled PerX as control; b) nosiheptide incubated with PerX; c) overexpressed perX in the nosiheptide producing strain Streptomyces actuosus ATCC25421.

PerA, another enzyme involved in the maturation of persiathiacins, shares homology with NosA, ${ }^{40}$ which cleaves the C-terminal tail of the core peptide. The enzyme cascade PerS1-PerS12 then directs the biosynthesis of modified sugars, their methylation, and attachment to the core peptide of persiathiacin. Four glycosyltransferases (PerS4, PerS6, PerS8, and PerS9) each install one sugar moiety onto the persiathiacin aglycone. While 
four methyl groups are present in the sugars (two on C2 and C3 of sugar 1; two on C3 and C4 of sugar 4), only three methyltransferases (PerS3, PerS5, and PerS7) were found in the sugar gene cascade. Thus, one of these enzymes presumably methylates the C3 hydroxy group of both sugars 1 and 4 . The remaining gene products are involved in the conversion of $\alpha$-D-glucose to D-olivose and D-amicetose (Figure 6).
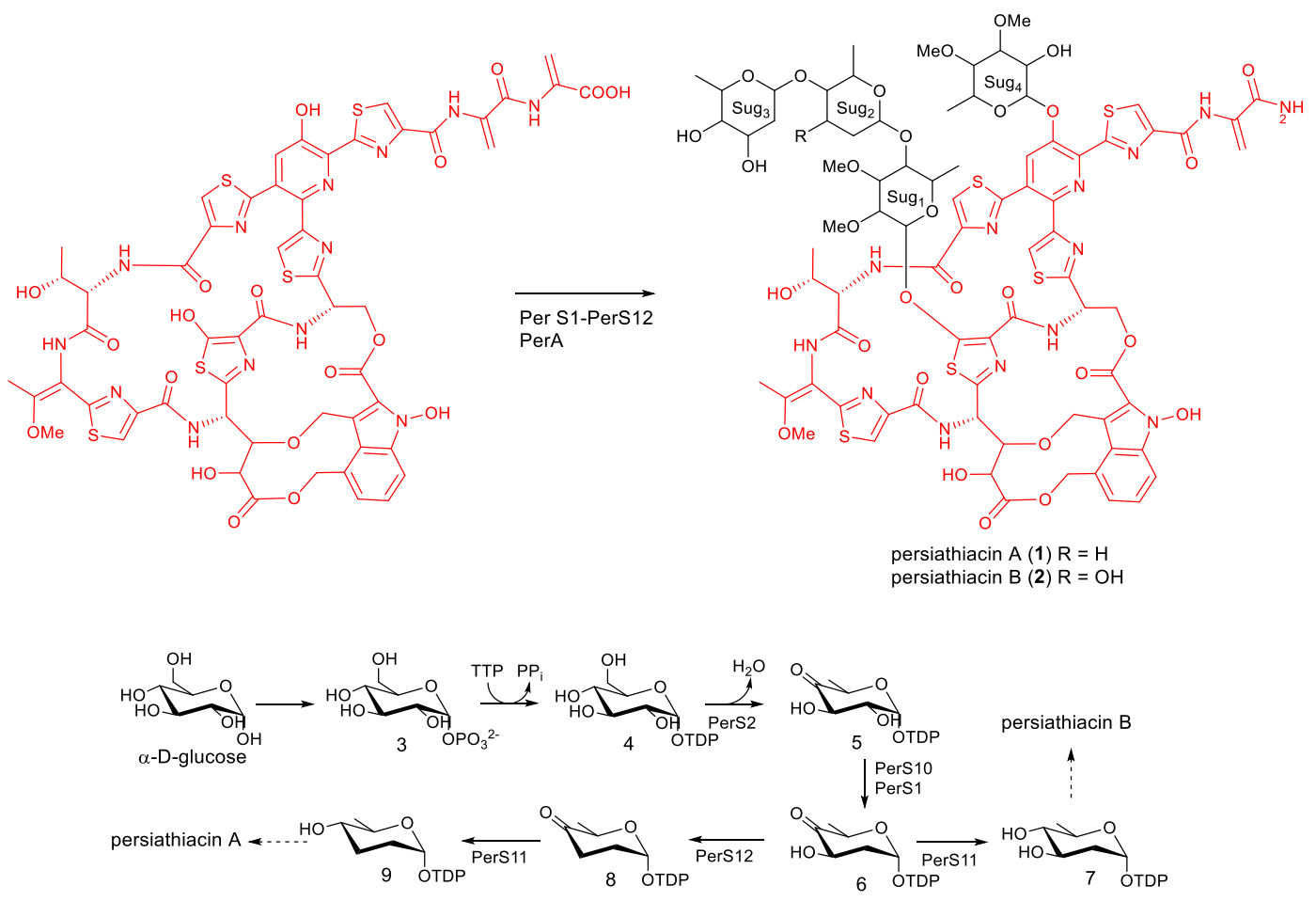

persiathiacin B

Figure 6. The genes products of perS1-perS12 are responsible for modification and attachment of sugars to persiathyacin aglycone, while the gene product of perA cleaves the C-terminal tail.

Housekeeping thymidylyltransferases initially convert $\alpha$-D-glucose-1-phosphate (3) to TDP- $\alpha$-D-glucose (4), which is then converted to TDP-4-keto-6-deoxy- $\alpha$-D-glucose (5) by the TDP-glucose-4,6-dehydratase PerS2. The TDP-4-keto-6-deoxy-D-glucose-2,3dehydratase PerS10 and TDP-4-keto-6-deoxy-D-glucose-3-ketoreductase PerS1 catalyse formation of TDP-4-keto-2,6-deoxy- $\alpha$-D-glucose (6) from 5 . The intermediate 6 is a substrate for two different enzymes: the TDP-4-keto-6-deoxyreductase PerS11 can catalyse ketone reduction to produce TDP-D-olivose (7); alternatively, the TDP-4keto-2,6-deoxy-D-glucose-3-dehydratase PerS12 can dehydrate 6 at position C3 to form 
TDP-4-keto-2,3,6-deoxy- $\alpha$-D-glucose (8), which is then reduced to TDP-D-amicetose (9). Both 7 and 9 are then attached to the persiathiacin scaffold by one of the aforementioned glycosyltransferases. Glycosyltransferases are known to possess broad substrate specificities. ${ }^{41}$ Persiathiacin B differs from persiathiacin A at sugar position 2, which appears to result from relaxed specificity of the glycosyltransferase that attaches D-olivose instead of D-amicetose.

\section{Biological activity and mode of action}

The major metabolite persiathiacin A was tested against MRSA and other members of the ESKAPE panel of pathogens by measuring minimum inhibitory concentration (MIC) values. ${ }^{42}$ Persiathiacin A showed potent antibiotic activity against MRSA (MIC of $0.025 \mu \mathrm{g} / \mathrm{mL}$ ) and moderate activity against Enterococcus faecium (MIC of $32 \mu \mathrm{g} / \mathrm{mL}$ ). The compound was inactive against all Gram-negative bacteria in the panel at clinically relevant MIC cutoffs. As nocathiacin has been reported to be active against susceptible and drug resistant clinical strains of M. tuberculosis, ${ }^{43-44}$ we evaluated the activity of persiathiacin A against several clinical strains of M. tuberculosis using the resazurin microtiter assay. ${ }^{45}$ Persiathiacin was found to be active against all tested $M$. tuberculosis clinical isolates, including the susceptible strain H37Rv, four isoniazid-resistant strains, and the two multi-drug resistant strains CHUV80059744 and CHUV80037024 (resistant to both isoniazid and rifampicin) (Table 1).

The antibacterial activity of a number of thiopeptides is known to result from inhibition of ribosomal protein biosynthesis. ${ }^{46-48}$ We thus investigated the inhibitory capacity of persiathiacin A against the bacterial ribosome using an E. coli cell-free transcription/translation assay. Concentration-dependent inhibition of the ribosome by persiathiacin A was observed with an $\mathrm{IC}_{50}$ value of $1.8 \pm 0.3 \mu \mathrm{M}$ (Figure S15). Persiathiacin A exhibited negligible toxicity 
toward the A2780 ovarian cancer cell line up to the maximum tested concentration of $400 \mu \mathrm{M}$ (Figure S16).

Table 1. MIC values of persiathiacin A against different clinical isolates of M. tuberculosis.

\begin{tabular}{lllccc} 
& & & \multicolumn{3}{c}{ MIC $(\mu \mathrm{g} / \mathrm{mL})$} \\
\cline { 4 - 6 } Strain & Mutation & Resistance & Persiathiacin A & Rifampicin & Isoniazid \\
\hline H37Rv & None & None & 3.6 & 0.0008 & 0.04 \\
HUGMB6726 & inhA & Isoniazid & 3.7 & 0.0008 & 2.2 \\
HUGMB3649 & inhA & Isoniazid & 3.9 & 0.001 & 0.08 \\
CHUV80045776 & katG & Isoniazid & 1.6 & 0.001 & 2.5 \\
HUGMI1020 & katG & Isoniazid & 1.7 & 0.002 & 1.3 \\
CHUV80059744 & rpoB and $k a t G$ & Isoniazid, Rifampicin & 2.2 & 14 & $>10$ \\
CHUV80037024 & rpoB, kat $G$ and inhA & Isoniazid, Rifampicin & 3.1 & $>10$ & $>10$ \\
\hline
\end{tabular}

\section{Conclusions}

As thiopeptide antibiotics generally suffer from poor water solubility, glycosylated analogues are of great interest as a starting point for biosynthetic engineering and/or semisynthetic efforts to improve solubility. In this study, we identified the two novel polyglycosylated thiopeptides persiathiacins A and B, produced by Actinokineospora sp. UTMC 2475 and Actinokineospora sp. UTMC 2448. The major metabolite, persiathiacin A, was tested against several pathogenic strains and showed potent activity against MRSA. The compound also showed good activity against several drug-resistant and multidrug-resistant clinical isolates of $M$. tuberculosis. No information is available on the biosynthesis of philipimycin, the only other reported polyglycosylated thiopeptide. We therefore investigated the biosynthetic pathway of the persiathiacins and uncovered the responsible cluster containing 33 genes. Comparative analysis of the enzymes encoded by this gene cluster to those of related thiopeptides nosiheptide and nocathiacin, combined with in vitro and in vivo experiments, permitted identification of a novel cytochrome $\mathrm{P}_{450}$ enzyme responsible for hydroxylation of the central thiazole ring in persiathiacin. 


\section{Acknowledgements}

Y.D. was supported by a grant from the MRC (MR/N501839/1 to G.L.C.). The Bruker MaXis Impact UHPLC-ESI-Q-TOF-MS instrument used in this research was funded by the BBSRC (B/K002341/1 to G.L.C.). G.L.C. was the recipient of a Wolfson Research Merit Award from the Royal Society (WM130033). We thank Simone Schrader and Nicole Heyer for excellent technical assistance for PacBio genome sequencing.

\section{References}

1. Kaufmann, S. H. E.; ven Helden, P., Handbook of Tuberculosis: Clinics, Diagnostics, Therapy, and Epidemiology. Wiley: 2008.

2. Treatment of Tuberculosis Guidelines; World Health Organization: 2007.

3. Dashti, Y.; Grkovic, T.; Quinn, R. J., Predicting natural product value, an exploration of anti-TB drug space. Nat. Prod. Rep. 2014, 31 (8), 990-998.

4. Arnison, P. G.; Bibb, M. J.; Bierbaum, G.; Bowers, A. A.; Bugni, T. S.; Bulaj, G.; Camarero, J. A.; Campopiano, D. J.; Challis, G. L.; Clardy, J.; Cotter, P. D.; Craik, D. J.; Dawson, M.; Dittmann, E.; Donadio, S.; Dorrestein, P. C.; Entian, K.-D.; Fischbach, M. A.; Garavelli, J. S.; Göransson, U.; Gruber, C. W.; Haft, D. H.; Hemscheidt, T. K.; Hertweck, C.; Hill, C.; Horswill, A. R.; Jaspars, M.; Kelly, W. L.; Klinman, J. P.; Kuipers, O. P.; Link, A. J.; Liu, W.; Marahiel, M. A.; Mitchell, D. A.; Moll, G. N.; Moore, B. S.; Müller, R.; Nair, S. K.; Nes, I. F.; Norris, G. E.; Olivera, B. M.; Onaka, H.; Patchett, M. L.; Piel, J.; Reaney, M. J. T.; Rebuffat, S.; Ross, R. P.; Sahl, H.-G.; Schmidt, E. W.; Selsted, M. E.; Severinov, K.; Shen, B.; Sivonen, K.; Smith, L.; Stein, T.; Süssmuth, R. D.; Tagg, J. R.; Tang, G.-L.; Truman, A. W.; Vederas, J. C.; Walsh, C. T.; Walton, J. D.; Wenzel, S. C.; Willey, J. M.; van der Donk, W. A., Ribosomally synthesized and posttranslationally modified peptide natural products: overview and recommendations for a universal nomenclature. Nat. Prod. Rep. 2013, 30 (1), 108-160.

5. Ortega, Manuel A.; van der Donk, Wilfred A., New Insights into the Biosynthetic Logic of Ribosomally Synthesized and Post-translationally Modified Peptide Natural Products. Cell Chem. Biol. 2016, 23 (1), 31-44.

6. Burkhart, B. J.; Hudson, G. A.; Dunbar, K. L.; Mitchell, D. A., A prevalent peptide-binding domain guides ribosomal natural product biosynthesis. Nat. Chem. Biol. 2015, 11 (8), 564-570.

7. Li, C.; Kelly, W. L., Recent advances in thiopeptide antibiotic biosynthesis. Nat. Prod. Rep. 2010, 27 (2), 153-164.

8. Zhang, Q.; Liu, W., Biosynthesis of thiopeptide antibiotics and their pathway engineering. Nat. Prod. Rep. 2013, 30 (2), 218-26.

9. Hudson, G. A.; Zhang, Z.; Tietz, J. I.; Mitchell, D. A.; van der Donk, W. A., In Vitro Biosynthesis of the Core Scaffold of the Thiopeptide Thiomuracin. J. Am. Chem. Soc. 2015, 137 (51), 16012-16015.

10. Zhang, Z.; Hudson, G. A.; Mahanta, N.; Tietz, J. I.; van der Donk, W. A.; Mitchell, D. A., Biosynthetic Timing and Substrate Specificity for the Thiopeptide Thiomuracin. J. Am. Chem. Soc. 2016, 138 (48), 15511-15514.

11. Wever, W. J.; Bogart, J. W.; Bowers, A. A., Identification of Pyridine Synthase Recognition Sequences Allows a Modular Solid-Phase Route to Thiopeptide Variants. J. Am. Chem. Soc. 2016, 138 (41), 13461-13464. 
12. Bewley, K. D.; Bennallack, P. R.; Burlingame, M. A.; Robison, R. A.; Griffitts, J. S.; Miller, S. M., Capture of micrococcin biosynthetic intermediates reveals $\mathrm{C}$-terminal processing as an obligatory step for in vivo maturation. Proc. Natl. Acad. Sci. U.S.A. 2016, 113 (44), 12450-12455.

13. Liu, W.; Xue, Y.; Ma, M.; Wang, S.; Liu, N.; Chen, Y., Multiple oxidative routes towards the maturation of nosiheptide. Chembiochem 2013, 14 (13), 1544-1547.

14. Bagley, M. C.; Dale, J. W.; Merritt, E. A.; Xiong, X., Thiopeptide Antibiotics. Chem. Rev. 2005, 105 (2), 685-714.

15. Haste, N. M.; Thienphrapa, W.; Tran, D. N.; Loesgen, S.; Sun, P.; Nam, S.-J.; Jensen, P. R.; Fenical, W.; Sakoulas, G.; Nizet, V.; Hensler, M. E., Activity of the thiopeptide antibiotic nosiheptide against contemporary strains of methicillin-resistant Staphylococcus aureus. J. Antibiot. 2012, 65 (12), 593-598.

16. Pucci, M. J.; Bronson, J. J.; Barrett, J. F.; DenBleyker, K. L.; Discotto, L. F.; Fung-Tomc, J. C.; Ueda, Y., Antimicrobial evaluation of nocathiacins, a thiazole peptide class of antibiotics. Antimicrob. Agents Chemother. 2004, 48 (10), 3697-3701.

17. Zhang, C.; Occi, J.; Masurekar, P.; Barrett, J. F.; Zink, D. L.; Smith, S.; Onishi, R.; Ha, S.; Salazar, O.; Genilloud, O.; Basilio, A.; Vicente, F.; Gill, C.; Hickey, E. J.; Dorso, K.; Motyl, M.; Singh, S. B., Isolation, structure, and antibacterial activity of philipimycin, a thiazolyl peptide discovered from Actinoplanes philippinensis MA7347. J. Am. Chem. Soc. 2008, 130 (36), 12102-12110.

18. Just-Baringo, X.; Albericio, F.; Álvarez, M., Thiopeptide Engineering: A Multidisciplinary Effort towards Future Drugs. Angew. Chem. Int. Ed. 2014, 53 (26), 6602-6616.

19. LI, W.; LEET, J., E.; LAM, K., S. Nocathiacin antibiotic derivatives prepared by microbial biotransformation. 2000.

20. Leet, J. E.; Li, W.; Ax, H. A.; Matson, J. A.; Huang, S.; Huang, R.; Cantone, J. L.; Drexler, D.; Dalterio, R. A.; Lam, K. S., Nocathiacins, new thiazolyl peptide antibiotics from Nocardia sp. II. Isolation, characterization, and structure determination. J. Antibiot. 2003, 56 (3), 232-242.

21. Mocek, U.; Chen, L. C.; Keller, P. J.; Houck, D. R.; Beale, J. M.; Floss, H. G., ${ }^{1} \mathrm{H}$ and ${ }^{13} \mathrm{C}$ NMR assignments of the thiopeptide antibiotic nosiheptide. J. Antibiot. 1989, 42 (11), 1643-1648.

22. Weber, T.; Blin, K.; Duddela, S.; Krug, D.; Kim, H. U.; Bruccoleri, R.; Lee, S. Y.; Fischbach, M. A.; Müller, R.; Wohlleben, W.; Breitling, R.; Takano, E.; Medema, M. H., antiSMASH 3.0-a comprehensive resource for the genome mining of biosynthetic gene clusters. Nucleic Acids Res 2015, 43 (W1), W237W243.

23. Zhang, Q.; Li, Y.; Chen, D.; Yu, Y.; Duan, L.; Shen, B.; Liu, W., Radical-mediated enzymatic carbon chain fragmentation-recombination. Nat. Chem. Biol. 2011, 7 (3), 154-160.

24. Nicolet, Y.; Zeppieri, L.; Amara, P.; Fontecilla-Camps, J. C., Crystal structure of tryptophan lyase (NosL): evidence for radical formation at the amino group of tryptophan. Angew. Chem. Int. Ed. 2014, $53(44), 11840-4$.

25. Ji, X.; Li, Y.; Ding, W.; Zhang, Q., Substrate-Tuned Catalysis of the Radical S-Adenosyl-LMethionine Enzyme NosL Involved in Nosiheptide Biosynthesis. Angew. Chem. Int. Ed. 2015, 54 (31), 9021-9024.

26. Bhandari, D. M.; Xu, H.; Nicolet, Y.; Fontecilla-Camps, J. C.; Begley, T. P., Tryptophan Lyase (NosL): Mechanistic Insights from Substrate Analogues and Mutagenesis. Biochemistry 2015, 54 (31), 4767-4769.

27. Ji, X.; Li, Y.; Jia, Y.; Ding, W.; Zhang, Q., Mechanistic Insights into the Radical S-adenosyl-Imethionine Enzyme NosL From a Substrate Analogue and the Shunt Products. Angew. Chem. Int. Ed. 2016, 55 (10), 3334-3337.

28. Sicoli, G.; Mouesca, J.-M.; Zeppieri, L.; Amara, P.; Martin, L.; Barra, A. L.; Fontecilla-Camps, J. C.; Gambarelli, S.; Nicolet, Y., Fine-tuning of a radical-based reaction by radical S-adenosyl-Lmethionine tryptophan lyase. Science 2016, 351 (6279), 1320-1323.

29. Ding, W.; Ji, X.; Li, Y.; Zhang, Q., Catalytic Promiscuity of the Radical S-adenosyl-L-methionine Enzyme NosL. Front. Chem. 2016, 4 (27). 
30. Bhandari, D. M.; Fedoseyenko, D.; Begley, T. P., Tryptophan Lyase (NosL): A Cornucopia of 5'Deoxyadenosyl Radical Mediated Transformations. J. Am. Chem. Soc. 2016, 138 (50), 16184-16187.

31. Qianzhu, H.; Ji, W.; Ji, X.; Chu, L.; Guo, C.; Lu, W.; Ding, W.; Gao, J.; Zhang, Q., Reactivity of the nitrogen-centered tryptophanyl radical in the catalysis by the radical SAM enzyme NosL. ChemComm 2017, 53 (2), 344-347.

32. Badding, E. D.; Grove, T. L.; Gadsby, L. K.; LaMattina, J. W.; Boal, A. K.; Booker, S. J., Rerouting the Pathway for the Biosynthesis of the Side Ring System of Nosiheptide: The Roles of Nosl, NosJ, and NosK. J. Am. Chem. Soc. 2017, 139 (16), 5896-5905.

33. Ding, W.; Ji, W.; Wu, Y.; Wu, R.; Liu, W.-Q.; Mo, T.; Zhao, J.; Ma, X.; Zhang, W.; Xu, P.; Deng, Z.; Tang, B.; Yu, Y.; Zhang, Q., Biosynthesis of the nosiheptide indole side ring centers on a cryptic carrier protein NosJ. Nat. Commun. 2017, 8 (1), 437.

34. Qiu, Y.; Du, Y.; Zhang, F.; Liao, R.; Zhou, S.; Peng, C.; Guo, Y.; Liu, W., Thiolation Protein-Based Transfer of Indolyl to a Ribosomally Synthesized Polythiazolyl Peptide Intermediate during the Biosynthesis of the Side-Ring System of Nosiheptide. J. Am. Chem. Soc. 2017, 139 (50), 18186-18189.

35. LaMattina, J. W.; Wang, B.; Badding, E. D.; Gadsby, L. K.; Grove, T. L.; Booker, S. J., NosN, a Radical S-Adenosylmethionine Methylase, Catalyzes Both C1 Transfer and Formation of the Ester Linkage of the Side-Ring System during the Biosynthesis of Nosiheptide. J. Am. Chem. Soc. 2017, 139 (48), 17438-17445.

36. Yu, Y.; Duan, L.; Zhang, Q.; Liao, R.; Ding, Y.; Pan, H.; Wendt-Pienkowski, E.; Tang, G.; Shen, B.; Liu, W., Nosiheptide biosynthesis featuring a unique indole side ring formation on the characteristic thiopeptide framework. ACS Chem. Biol. 2009, 4 (10), 855-864.

37. Ding, Y.; Yu, Y.; Pan, H.; Guo, H.; Li, Y.; Liu, W., Moving posttranslational modifications forward to biosynthesize the glycosylated thiopeptide nocathiacin I in Nocardia sp. ATCC202099. Mol. Biosyst. 2010, 6 (7), 1180-1185.

38. Bai, X.; Guo, H.; Chen, D.; Yang, Q.; Tao, J.; Liu, W., Isolation and structure determination of two new nosiheptide-type compounds provide insights into the function of the cytochrome P450 oxygenase NocV in nocathiacin biosynthesis. Org. Chem. Front. 2020, 7 (3), 584-589.

39. Guo, H.; Bai, X.; Yang, Q.; Xue, Y.; Chen, D.; Tao, J.; Liu, W., NocU is a cytochrome P450 oxygenase catalyzing $\mathrm{N}$-hydroxylation of the indolic moiety during the maturation of the thiopeptide antibiotics nocathiacins. Org. Biomol. Chem. 2021.

40. Yu, Y.; Guo, H.; Zhang, Q.; Duan, L.; Ding, Y.; Liao, R.; Lei, C.; Shen, B.; Liu, W., NosA catalyzing carboxyl-terminal amide formation in nosiheptide maturation via an enamine dealkylation on the serine-extended precursor peptide. J. Am. Chem. Soc. 2010, 132 (46), 16324-16326.

41. Thibodeaux, C. J.; Melançon, C. E.; Liu, H.-W., Natural-product sugar biosynthesis and enzymatic glycodiversification. Angew. Chem. Int. Ed. 2008, 47 (51), 9814-9859.

42. Boucher, H. W.; Talbot, G. H.; Bradley, J. S.; Edwards, J. E.; Gilbert, D.; Rice, L. B.; Scheld, M.; Spellberg, B.; Bartlett, J., Bad Bugs, No Drugs: No ESKAPE! An Update from the Infectious Diseases Society of America. Clin. Infect. Dis. 2009, 48 (1), 1-12.

43. Pucci, M. J.; Bronson, J. J.; Barrett, J. F.; DenBleyker, K. L.; Discotto, L. F.; Fung-Tomc, J. C.; Ueda, Y., Antimicrobial evaluation of nocathiacins, a thiazole peptide class of antibiotics. Antimicrob. Agents Chemother. 2004, 48 (10), 3697-701.

44. Singh, S. B.; Xu, L.; Meinke, P. T.; Kurepina, N.; Kreiswirth, B. N.; Olsen, D. B.; Young, K., Thiazomycin, nocathiacin and analogs show strong activity against clinical strains of drug-resistant Mycobacterium tuberculosis. J. Antibiot. 2017, 70, 671-674.

45. Martin, A.; Camacho, M.; Portaels, F.; Palomino, J. C., Resazurin microtiter assay plate testing of Mycobacterium tuberculosis susceptibilities to second-line drugs: rapid, simple, and inexpensive method. Antimicrob. Agents Chemother. 2003, 47 (11), 3616-3619.

46. Baumann, S.; Schoof, S.; Harkal, S. D.; Arndt, H. D., Mapping the binding site of thiopeptide antibiotics by proximity-induced covalent capture. J. Am. Chem. Soc. 2008, 130 (17), 5664-6. 
47. Harms, J. M.; Wilson, D. N.; Schluenzen, F.; Connell, S. R.; Stachelhaus, T.; Zaborowska, Z.; Spahn, C. M.; Fucini, P., Translational regulation via L11: molecular switches on the ribosome turned on and off by thiostrepton and micrococcin. Mol. Cell 2008, 30 (1), 26-38.

48. Walter, J. D.; Hunter, M.; Cobb, M.; Traeger, G.; Spiegel, P. C., Thiostrepton inhibits stable 70 S ribosome binding and ribosome-dependent GTPase activation of elongation factor $\mathrm{G}$ and elongation factor 4. Nucleic Acids Res. 2012, 40 (1), 360-70. 